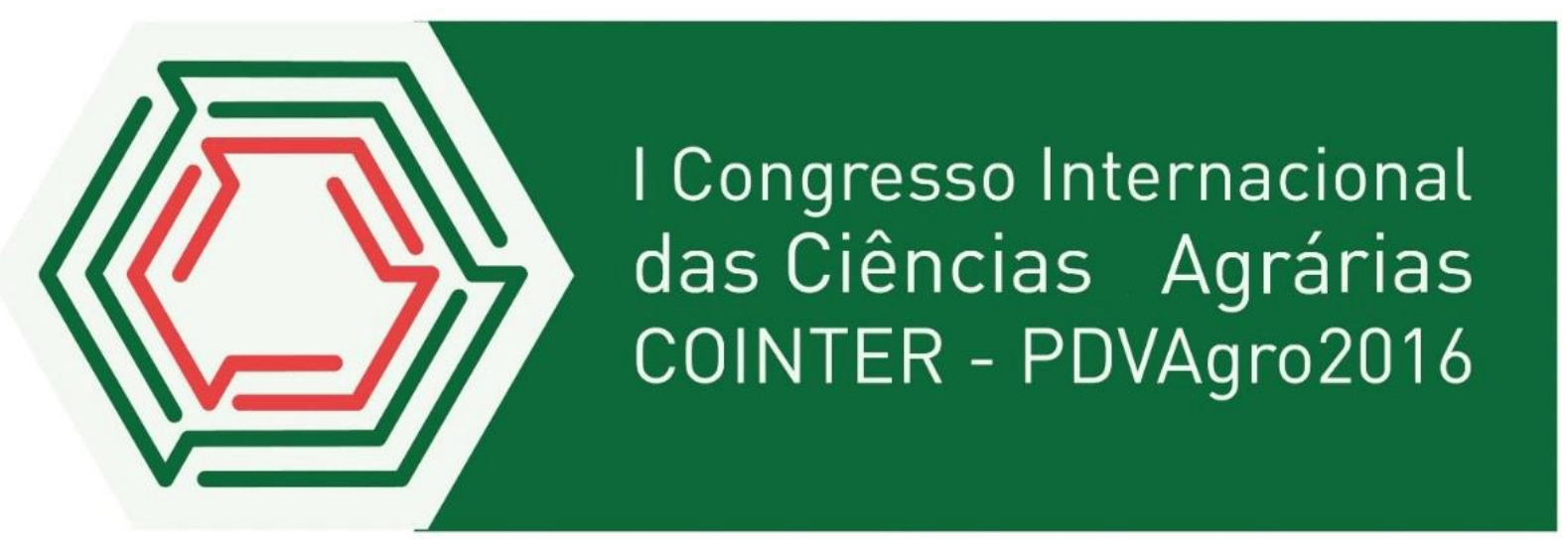

\title{
ELABORAÇÃO DA CARTA DE VEGETAÇÃO NA REPRESENTAÇÃO DA AGRICULTURA DE SEQUEIRO E CAATINGA ARBUSTIVA E SEMI-ARBUSTIVA NA BACIA HIDROGRÁFICA DO RIACHO DO JACU
}

\author{
Apresentação: Comunicação Oral \\ Edja Lillian Pacheco da Luz ${ }^{1}$; Victor Casimiro Piscoya ${ }^{2}$; José Ramon Barros Cantalice ${ }^{3}$
}

\begin{abstract}
Resumo
A região semiárida do nordeste brasileiro é caracterizada pela baixa precipitação anual, altas temperaturas e solos com grande potencial erosivo. Essas particularidades fizeram com que houvesse o desenvolvimento de um tipo de vegetação única no Brasil, e tipicamente adaptada a essas condições, a caatinga. Contudo essas mesmas características dificultam o estabelecimento de agriculturas de forma convencional como são cultivadas em outras regiões do país, uma alternativa que vem sendo empregada nessas regiões é a agricultura de sequeiro ou seja sem uso de irrigação e com baixas taxas de precipitação. Nesse contexto esse trabalho buscou a partir da elaboração de uma carta de vegetação conhecer a área ocupada pela agricultura de sequeiro e o percentual representado por ela na bacia hidrográfica do riacho do Jacu inserida entre os municípios de Serra Talhada e Floresta no estado de Pernambuco. A elaboração dessa carta de vegetação e uso foi feita através de uma fotointerpretação automática (processamento digital) de uma imagem realizada pelo programa GeoCover posteriormente foi feita a quantificação das informações contidas na carta para obtenção dos dados de área ocupada em $\mathrm{km}^{2}$ das classes vegetais encontradas e o percentual de representatividade dessas classes sobre a área da bacia. Com base nessas análises observou-se que o total da área que ainda abrange a vegetação nativa da região, representada na forma de caatinga arbustiva e caatinga semiarbustiva quando somadas representam $87,79 \%$ da cobertura vegetal presente na bacia do riacho do Jacu. Certamente as informações trazidas neste trabalho podem servir de auxílio em futuros estudos monitoramento de uso e ocupação do solo na região semiárida, projetos de recuperação de áreas degradadas e estudos de impacto ambiental.
\end{abstract}

Palavras-Chave: Agricultura, vegetação, bacia hidrográfica.

\footnotetext{
${ }^{1}$ Mestranda em Engenharia Ambiental, Universidade Federal Rural de Pernambuco, lillian2800@hotmail.com

${ }^{2}$ Doutor em Ciência do Solo, Universidade Federal Rural de Pernambuco, vcpiscoya@hotmail.com

${ }^{3}$ Doutor em Ciência do Solo, Universidade Federal Rural de Pernambuco, cantalice21@hotmail.com
} 


\section{Introdução}

A região semiárida do nordeste brasileiro caracteriza-se por apresentar um regime de chuvas com eventos de duração extremamente curta e com intensidade muito alta, além de uma irregular distribuição espaço-temporal, seguida por longos períodos de seca, tornando estas áreas ambientes particularmente propícios à erosão (HÖTZL, 2008). A vegetação do tipo caatinga ou gramíneas de pouco desenvolvimento sobre solos pouco evoluídos. O clima é caracterizado por extrema variabilidade na precipitação, sujeito a secas e períodos infrequentes de chuvas e subsequentes inundações.

Nessas áreas a alta evapotranspiração real representa a principal perda hidrológica (50$60 \%$ da precipitação média anual). Os processos hidrológicos são altamente variáveis no tempo e no espaço devido à alta variabilidade do regime de chuvas, além da influência da topografia e da distribuição espacial da geologia local, solo e uso da terra.

O aumento da intensidade do uso do solo e a redução da cobertura vegetal nativa do semiárido nordestino têm levado à degradação dos recursos naturais e, em especial à redução da fertilidade do solo (MENEZES \& SAMPAIO, 2002), além da profundidade do perfil geralmente raso, da dificuldade de drenagem e do excesso de sódio trocável (SILVA, 2000).

Sendo assim esse este estudo teve como objetivo elaborar a Carta de vegetação na bacia do riacho do Jacu afim de conhecer qual a representatividade da agricultura de sequeiro nessa área, assim como os valores de vegetação nativa presente na forma de caatinga arbustiva e caatinga semi-arbustiva.

\section{Fundamentação Teórica}

De acordo com a UNESCO (1979), a definição de aridez baseia-se na metodologia desenvolvida por Thornthwaite (1941) com posterior ajuste de Penman (1953), para caracterizar zonas bioclimáticas. Zonas semiáridas são aquelas em que a razão P/ETP situa-se entre 0,20 e 0,50. As médias de precipitação no semiárido variam de 300 a 800 mm ano-1 e as médias de evapotranspiração potencial variam de 1500 a $2000 \mathrm{~mm}$ ano-1, sendo o balanço hidrológico da região distribuído desta forma: (a) 70\% da precipitação sendo evaporada; (b) $20 \%$ evapo-transpirada, principalmente pela vegetação da caatinga; (c) $10 \%$ escoada superficialmente.

O semiárido brasileiro é um dos mais úmidos do planeta, com média anual de $700 \mathrm{~mm}$ ano-1, enquanto na maioria das zonas áridas de outros países a média anual é de 80 a $250 \mathrm{~mm}$ ano-1 (MELO FILHO \& SOUZA, 2006). O termo caatinga é originário do tupi-guarani e significa mata branca. O bioma Caatinga, único exclusivamente brasileiro, é o principal 
ecossistema existente na região Nordeste, estendendo-se pelo domínio de climas semiáridos, numa área de 73.683.649 ha, equivalente a 6,83\% do território nacional e ocupando os estados da BA, CE, PI, PE, RN, PB, SE, AL além dos estados de MA e MG que se encontram fora da região nordeste. A ocorrência de secas estacionais e periódicas estabelece regimes intermitentes aos rios e deixa a vegetação sem folhas.

No entanto é frequente a remoção da cobertura vegetal e implementação de uma agricultura sem controle da erosão, que promove escoamento superficial na época chuvosa, transportando sedimentos e nutrientes adsorvidos que contribuem para o assoreamento e eutrofização dos rios e represas situadas a jusante. Entretanto, a escassez de água no período seco associado ao processo natural da evapotranspiração, conduz a uma baixa capacidade de diluição, podendo resultar numa deterioração extrema da qualidade da água e eliminação das comunidades biológicas naturais (GASITH \& RESH, 1999).

Em relação aos principais problemas relacionados com a qualidade da água no semiárido brasileiro, destacam-se: i) a salinização dos corpos hídricos, com especial incidência em alguns açudes; ii) elevados níveis de turbidez e assoreamento em importantes bacias; iii) o processo crescente de poluição dos recursos hídricos, causado principalmente por esgotos domésticos, industriais, matadouros, lixo, fertilizantes químicos e agrotóxicos (VIEIRA \& GONDIM FILHO, 2006).

Considera-se Bacia hidrográfica é a porção geográfica delimitada por divisores de água, englobando toda a área de drenagem de um curso d'água. É uma unidade geográfica natural e seus limites foram estabelecidos pelo escoamento das águas sobre a superfície, ao longo do tempo. É, portanto, o resultado da interação da água com outros recursos naturais (SANTANA, 2003).

Cada bacia hidrográfica se interliga com outra de ordem hierárquica superior, constituindo, em relação à última, uma sub-bacia. Portanto, os termos bacia e sub-bacia hidrográfica são relativos e relacionam-se a ordens hierárquicas dentro de uma determinada malha hídrica (FERNANDES \& SILVA, 1994).

As atividades do agricultor não são isoladas, ele trabalha com sistemas de produção e sua propriedade está inserida num contexto mais amplo, que são as bacias hidrográficas (SANTANA, 2003). O comportamento hidrológico de uma bacia hidrográfica é função de suas características geomorfológicas (forma, relevo, área, geologia, rede de drenagem, solo, etc.) e do tipo da cobertura vegetal existente (LIMA, 1976).

A compreensão dos efeitos qualitativos do uso do solo é um mecanismo importante na estratégia para implementação de práticas de conservação na escala de bacia, por parte dos agricultores, porque são eles que definem a organização espacial e temporal de sua 
propriedade. Quando ocorre o planejamento adequado de uma propriedade agrícola, utilizando técnicas adequadas de ocupação e manejo do solo, de acordo com sua aptidão agrícola, a produção de sedimentos pode se aproximar aos valores de áreas preservadas (MORGAN, 2005).

Por conseguinte, os solos das bacias hidrográficas, a partir de uma perspectiva que considera também aspectos qualitativos do uso, manejo e ocupação do solo, nos fornecem informações importantes que nos auxiliam na gestão ambiental de monitoramento hidrológico em toda a bacia especialmente dos processos referentes à transferência de sedimentos da bacia vertente para a calha fluvial, além dos processos monitorados no exutório (MINELLA ET AL., 2008).

No semiárido brasileiro, as bacias e microbacias rurais são exploradas apenas nas épocas das chuvas (agricultura de sequeiro), com pouco uso de tecnologia, e com as chamadas culturas de subsistência: feijão macassar, milho, sorgo, mandioca entre outros, de baixíssimo valor agregado, aliadas à pecuária extensiva. Como em outras regiões semiáridas do mundo, o trópico semiárido brasileiro apresenta em geral solos rasos e pedregosos, com baixa capacidade de retenção de água, baixo teor de matéria orgânica e alta susceptibilidade à erosão, fato explicado pela predominância de terrenos de rochas cristalinas. No estado de Pernambuco, esse tipo geológico representa $85 \%$ do total, contra $15 \%$ para as "bacias sedimentares" que tem como característica acumular maiores volumes de água (GOMES, 1990).

A agricultura de sequeiro é o cultivo sem irrigação em regiões onde a precipitação anual é inferior a $500 \mathrm{~mm}$, e que requerem técnicas de cultivo específicas que permitam um uso eficaz e eficiente da limitada umidade do solo (QUARANTA, 2000). Existem nestas áreas poucas opções de diversificação de cultivos compatíveis com as restrições de solo, clima e com os sistemas produtivos adotados pelos agricultores (SILVA, 2000).

O desmatamento indiscriminado para a formação de novas lavouras, aliado à retirada de madeira para benfeitorias, lenha e carvão, e às queimadas sucessivas com manejo inadequado do solo têm contribuído, juntamente com as secas prolongadas, para comprometer o frágil equilíbrio do meio ambiente da região. Assim, a destruição da caatinga na região semiárida do Nordeste brasileiro tem contribuído para acelerar a erosão do solo trazendo, como consequências, o seu empobrecimento e o assoreamento de mananciais (ALBUQUERQUE et al., 2001).

Além disso, a agricultura dependente de chuva, a falta de água para o consumo humano e para pequenas criações constitui a principal causa da baixa qualidade de vida do meio rural das zonas áridas e semiáridas, que correspondem a 55\% das terras em todo o mundo e $13 \%$ do território nacional brasileiro (SILVA et al., 1993). No Nordeste, a produtividade agrícola é 
limitada pela irregularidade na distribuição espaço - temporal da chuva, considerada mais grave do que sua escassez propriamente dita (SILVA \& RÊGO NETO, 1992). Por isso a agriculta de sequeiro é uma alternativa muitas vezes empregas no semiárido nordestino.

\section{Metodologia}

A área experimental encontra-se inserida na bacia hidrográfica do riacho Jacu localizada no limite municipal entre as cidades de Serra Talhada e Floresta, formando parte da bacia do São Pedro, inserida na bacia hidrográfica do Pajeú. O acesso se dá pela rodovia estadual PE 390 - km 20, na região da serra da Lagartixa, pertencente ao limite entre os municípios de Serra Talhada e Floresta, com coordenadas geográficas " $38^{\circ} 14^{\prime} 39.3$ ” de longitude Oeste e “0800”15.9” de latitude Sul (Figura 1).

O clima da região, de acordo com a classificação de Köppen, enquadra-se no tipo Bwh, denominado semiárido, quente e seco, com chuvas de verão-outono com pluviosidade

média anual de $647 \mathrm{~mm}$ ano ${ }^{-1}$ para o período de 1912 a 1991 (SUDENE, 1990) e temperatura média anual superior a $25^{\circ} \mathrm{C}$.

Tendo em vista a área de estudo, foi elaborado a carta de vegetação e uso da bacia hidrográfica do jacu, que corresponde a um mosaico de imagens Landsat que foram ortorretificadas e processadas com um alto padrão de qualidade (GeoCover Technical Guide) adotados para a execução do georreferenciamento.

No caso da bacia do Jacu a carta foi baseada na individualização das unidades fitológicas (Caatinga arbustiva, caatinga semi-arbustiva e agricultura de sequeiro) e de uso em função de suas características tonais e texturais com verificação prévia em campo para validar os resultados obtidos na etapa inicial.

Figura 1. Localização da bacia hidrográfica do riacho Jacu inserida na bacia do Pajeú. Fonte Própria. 


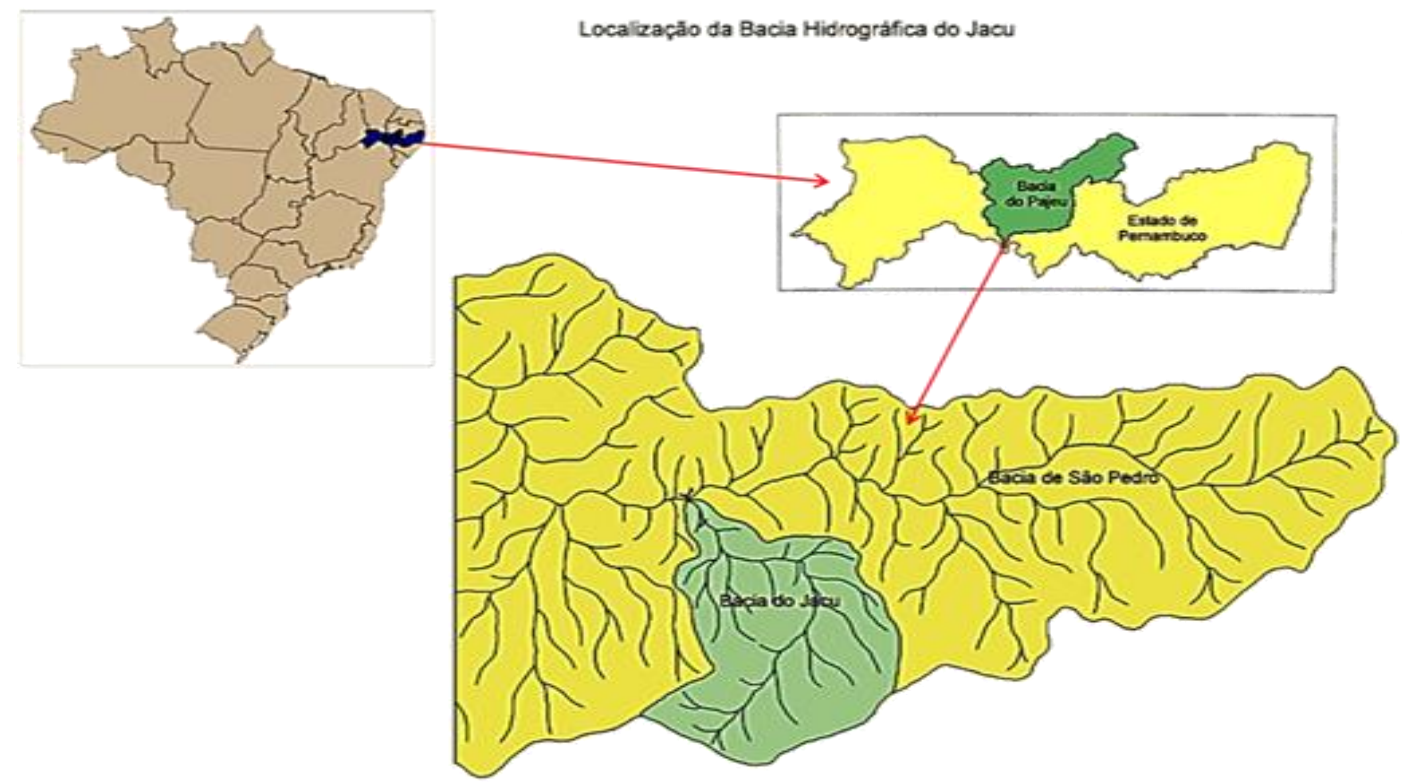

\section{Resultados e Discussão}

Os solos das bacias hidrográficas, a partir de uma perspectiva que considera também seus aspectos qualitativos, o uso e ocupação do solo, nos fornecem informações importantes que nos auxiliam na gestão ambiental de monitoramento hidrológico em toda a bacia especialmente dos processos referentes à transferência de sedimentos da bacia vertente para a calha fluvial, além dos processos monitorados no exutório (MINELLA ET AL., 2008).

Tendo em vista essas informações foi elaborado a Carta de vegetação e uso da bacia hidrográfica semiárida do Jacu (Figura 2). Feito através de uma fotointerpretação automática (processamento digital) de uma imagem por meio do programa GeoCover. Nesta ocasião foram individualizadas três unidades (caatinga arbustiva, caatinga semiarbustiva e agricultura de sequeiro).

Figura 2. Carta de Vegetação e Uso da Bacia Hidrográfica Semiárida do riacho Jacu. Fonte Própria 


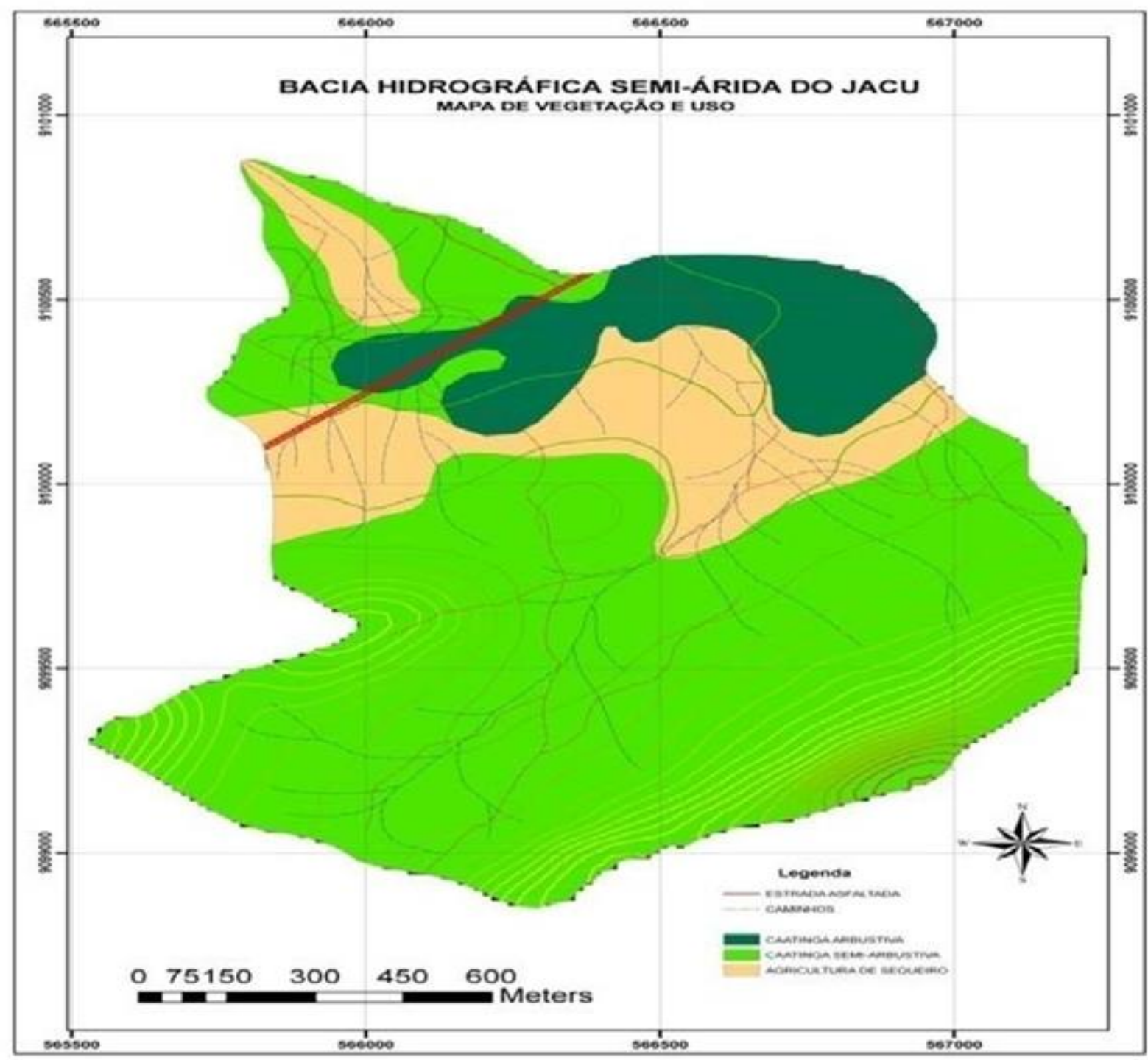

Como resultado da quantificação desta carta foi obtido os valores expressos na

Tabela 1. Foi possível observar que a agricultura de sequeiro representa uma área de $364.611 \mathrm{Km}^{2}$, o que representa 17,24\% da área da bacia hidrográfica do Jacú.

Contudo a caatinga semi-arbustiva foi a vegetação com o maior percentual encontrado representando $70,55 \%$ da área total da bacia. Já o menor percentual observado foi de $12,21 \%$ sendo de vegetação do tipo caatinga arbustiva.

Tabela 1. Distribuição das classes de vegetação e uso da bacia hidrográfica semiárida do riacho Jacu. Fonte Própria

\begin{tabular}{llc}
\hline Intervalo & Área $\left(\mathbf{k m}^{\mathbf{2}}\right)$ & Uso $(\boldsymbol{\%})$ \\
\hline Agricultura de sequeiro & 364.611 & 17,24 \\
Caatinga arbustiva & 258.248 & 12,21 \\
Caatinga semi-arbustiva & 1.492 .41 & 70,55 \\
Total & 2.115 .27 & 100,00 \\
\hline
\end{tabular}


Em função da crescente consciência sobre a importância da preservação ambiental e do avanço das leis que disciplinam a ação humana, alto interesse vem sendo despertado para programas de recomposição de áreas degradadas, exigindo que os conhecimentos técnicocientíficos sejam rapidamente repassados aos usuários desses programas.

Pesquisas como estas são de extrema importância, pois segundo Kageyama \& Costa (1993) esses conhecimentos devem ser locais, ou seja, cada região tem condições ambientais específicas, que devem ser estudadas isoladamente, sendo importante o estudo do desenvolvimento e sobrevivência de espécies nativas da região a ser reflorestada.

\section{Conclusões}

Podemos concluir que através de análises feitas a partir da elaboração da Carta de vegetação para a bacia do riacho do Jacu os maiores índices observados foram de vegetação nativa. Nas formas de caatinga arbustiva e caatinga semi-arbustiva.

Contudo a agricultura de sequeiro já abrange uma representação considerável da área total da bacia ocupando $364.611 \mathrm{~km}^{2}$ da mesma, ou seja $17,24 \%$ da cobertura vegetal presente em toda a bacia uma vez que esta é característica de áreas de baixa pluviosidade como é o caso da região semiárida, a qual está inserida a bacia do riacho do Jacu.

Além de contribuir para o conhecimento da situação real em que se encontra a cobertura vegetal da área de pesquisa. Esses dados podem servir de auxílio para futuros estudos de monitoramento de uso e ocupação do solo na região, priorizar os locais que mais necessitam de um plano de recuperação de áreas degradadas quando for o caso, e até mesmo estudos de impacto ambiental.

\section{Referências}

ALBUQUERQUE, A. W; LOMBARDI NETO, F; SRINIVASAN, V. S. Efeito do desmatamento da caatinga sobre as perdas de solo e água de um Luvissolo em Sumé (PB). Revista Brasileira de Ciência do Solo, Viçosa, v.25, n.1, p.121- 128, 2001.

FERNANDES, M.R. e SILVA, J. C. Programa Estadual de Manejo de Sub- Bacias Hidrográficas: Fundamentos e estratégias - Belo Horizonte: EMATER- MG. 1994. 24p.

GASITH, A.; RESH, V. H. Streams in the Mediterranean climate regions: Abiotic influences and biotic responses to predictable seasonal events. Ann. Rev.Ecol.Syst, 30: 51- 81.1999.

GOMES, C. C. Modelagem matemática para estudo de comportamento de aquífero aluvial represado por barragem subterrânea. Dissertação de Mestrado apresentado ao curso de PósGraduação em Engenharia Civil, Área de concentração Recursos Hídricos na Universidade Federal do Ceará, Fortaleza - CE. 1990. 
HÖTZL, H. Water resources management in theMiddle East under aspects of climatic changes. In: Zereini, F., Hötzl, H. (Eds.), Climatic Changes andWater Resources in the Middle East and North Africa. Environmental Science and Engineering. Springer, Berlin, Heidelberg, pp. 7792, 2008.

KAGEYAMA, P. Y.; COSTA, L. G. S. da. Revegetação: matas ciliares e de proteção ambiental. São Paulo: Fundação florestal, 26 p. 1993.

LIMA, W. P. Princípios de manejo de bacias hidrográficas. Piracicaba: ESALQ. USP, 1976.

MELO FILHO, J. F. de.; SOUZA, A. L. V. O manejo e a conservação do solo no semiárido baiano: desafios para a sustentabilidade. In: Revista Bahia Agrícola, v.7, n.3. Nov. 2006. Disponível em: http://www.seagri.ba.gov.br/pdf/socioeconomia04_v7n3.pdf. Acesso 09 dez. 2011.

MENEZES, R. S. C.; SAMPAIO, E. V. S. B. Simulação dos fluxos e balanços de fósforo em uma unidade de produção agrícola familiar no semiárido paraibano. In: SILVEIRA, L. M: PETERSEN, P \& SABOURIN, E., orgs. Agricultura familiar e agroecología no semiárido: Avanços a partir do Agreste da Paraíba. Rio de Janeiro, AS - PTA, p 249 - 260. 2002.

MINELLA, J. P. G; WALLING, DES E; MERTEN, G. H. Combining sediment source tracing techniques with traditional monitoring to assess the impact of improved land management on catchment sediment yields. Journal of Hydrology, 2008. v. 348, p. 546 - 563 . jornal homepage : www.elsevier.com/locate/jhdrol. Acesso em 14 set. 2011.

MORGAN, R. P. C. Soil erosion and conservation. 3.ed. Malden: Blackwell, 304 p. 2005.

PENMAN, H. L. The Physical bases of irrigation control. In: International Horticultural Congress, 13, 1953, London. Report. London: Royal Horticultural Society, p. 913 - 924. 1953.

QUARANTA, G. Agricultura de Sequeiro. Land Care in Desertification Affected Areas Lucinda. Série C, No. 4. 2000.

SANTANA, D. P. Manejo integrado de bacias hidrográficas. EMBRAPA/ Milho e Sorgo, Sete Lagoas, documento 30, p. 63, 2003.

SILVA, D. A. da; REGO NETO, J. Avaliação de barragens subterrâneas para fins de exploração agrícola . In: CONGRESSO NACIONAL DE IRRIGAÇÃO E DRENAGEM, 9. Natal. Anais. Fortaleza: ABID, p.335 - 361. 1992.

SILVA, F. B. R. E; RICHÉ, G. R; TONNEAU, J. P; SOUZA NETO, N. C. de; BRITO, L. T. de L; CORREIA, R. C; CAVAlCANTI, A. C; SILVA, F. H. B. B. da; SILVA, A. B. da; ARAÚJO FILHO, J. C. de. Zoneamento agroecológico do Nordeste: diagnóstico do quadro natural e agrossocio-econômico. Petrolina: Embrapa-CPATSA/Recife: Embrapa - CNPS , Coordenadoria Regional Nordeste, v.1, il. 1993.

SILVA, J.R.C. Erosão e produtividade do solo no semiárido. In: OLIVEIRA, T.S. de et al., (eds) Agricultura, sustentabilidade e o semiárido. Viçosa: MG; SBCS/Universidade Federal do Ceará, Fortaleza - CE, p.170-213. 2000.

SUDENE. Superintendência de Desenvolvimento do Nordeste. 1990. Caracterização do Semiárido Brasileiro. Disponível em: http://www.asabrasil.org.br. Acesso 10 out. 2011. 
THORNTHWAITE, C. W.; HOLZMAN, B. Evaporation and transpiration. In: Climate and Man: Yearbook of Agriculture. Washington: U.S. Department of Agriculture, p 545 550.1941 .

UNESCO. Aridity definition. (UN Documents). United Nations Educational, Scientifica and Cultural Oraganization, New York. 1979. Disponível em: http:// www.unesco.org/new/en/unesco/resources/publication. Acesso 15 dez. 2011.

VIEIRA, V. P. P. B.; GONDIM FILHO, J. C. G. Água doce no semiárido. p. 481- 505 in A. C. 2006. 